The Relationship between Knowledge, Self-Efficacy, and Psychological Distress among Pdk Committees in Penang: A Preliminary Study

Qarem Mohamed Mustafa, Siti Nur Fadzilah Muhsain, Muhammad Azwan Azri, Kartini llias, Muhammad lqbal Shaharudin

To Link this Article: http://dx.doi.org/10.6007/IJARBSS/v11-i10/11501 DOI:10.6007/IJARBSS/v11-i10/11501

Received: 22 August 2021, Revised: 24 September 2021, Accepted: 11 October 2021

Published Online: 28 October 2021

In-Text Citation: (Mustafa et al., 2021)

To Cite this Article: Mustafa, Q. M., Muhsain, S. N. F., Azri, M. A., Ilias, K., \& Shaharudin, M. I. (2021). The Relationship between Knowledge, Self-Efficacy, and Psychological Distress among Pdk Committees in Penang: A Preliminary Study. International Journal of Academic Research in Business and Social Sciences, 11(10), $1254-1263$.

Copyright: (c) 2021 The Author(s)

Published by Human Resource Management Academic Research Society (www.hrmars.com) This article is published under the Creative Commons Attribution (CC BY 4.0) license. Anyone may reproduce, distribute, translate and create derivative works of this article (for both commercial and non-commercial purposes), subject to full attribution to the original publication and authors. The full terms of this license may be seen at: http://creativecommons.org/licences/by/4.0/legalcode

Vol. 11, No. 10, 2021, Pg. $1254-1263$

Full Terms \& Conditions of access and use can be found at http://hrmars.com/index.php/pages/detail/publication-ethics 


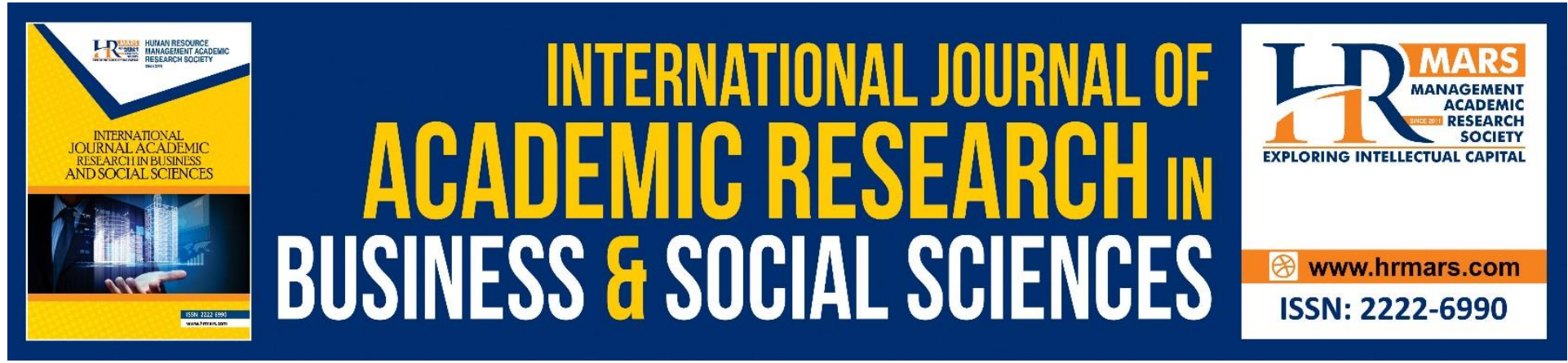

\title{
The Relationship between Knowledge, Self- Efficacy, and Psychological Distress among Pdk Committees in Penang: A Preliminary Study
}

Qarem Mohamed Mustafa

Faculty of Health Sciences, Universiti Teknologi MARA, Cawangan Pulau Pinang Malaysia

Siti Nur Fadzilah Muhsain

Faculty of Pharmacy, Universiti Teknologi MARA, Cawangan Pulau Pinang, Malaysia

Muhammad Azwan Azri

Faculty of Health Sciences, Universiti Teknologi MARA, Cawangan Pulau Pinang, Malaysia

Kartini Ilias

Faculty of Health Sciences, University Teknologi MARA, Cawangan Selangor, Malaysia

\section{Muhammad lqbal Shaharudin}

Faculty of Health Sciences, Universiti Teknologi MARA, Cawangan Pulau Pinang, Malaysia

\begin{abstract}
Abstarct
Caregiver at Pusat Dalam Komuniti (PDK) around Malaysia are responsible to take care of differently-abled children. Most of them are contributing their energy on voluntary basis. They may be at risk of stress similar to other health-related helping professions. This research examines the relationship between the knowledge, self-efficacy, and psychology distress experienced by caregivers at PDK within Penang. 32 caregiver trainees between the ages of 22 to 55 years old attended a Knowledge Transfer Program delivered by a certified occupational therapist. A questionnaire was provided at the end of the program to measure their knowledge, self-efficacy, and psychological stress. Pearson correlation shows a significant positive relationship between knowledge and self-efficacy $(r=.308, p<.05)$ and more specifically with procedural efficacy $(r=468, p<.05)$. Moreover, a significant positive correlation was also found between support request efficacy and psychological distress ( $r=$ $.362, p<.05)$. The findings suggest the importance of increasing the knowledge of caregivers especially in health-related helping profession through various programs to increase their belief of their ability to care for the differently-abled children and consequently safeguard the caregivers' well-being.
\end{abstract}


Keywords: PDK, Knowledge, Self-efficacy, Stress, Action Research

\section{Introduction}

The Department of Social Welfare (DSW) was formed 37 years ago on 1983 in Kuala Terengganu in collaboration with the World Health Organization (WHO) in which 55 disabled people benefitted at that time (Kuna, 1998). Since then, the Malaysia government was able to provide the services from DSW to every state and districts. One of the services provided by the DSW is Community Based Rehabilitation (CBR) also known as Pemulihan Dalam Komuniti (PDK) that focuses on providing disabled people with training and skills in rehabilitation. There are 16 PDK centers in the state of Penang. PDK aims to rehabilitate the disabled in order for them to act as part of the community, support and motivate disabled people and their family members, raise awareness of the community of the existence of disabled people who need support, and ultimately forming a caring society (JKM, 2017; Kuna, 1998). In the effort to achieve the objectives, DSW works together with the community in which family members, para-professionals, and volunteers act as primary activators to ensure the implementation of PDK. Due to this, the individuals who are part of the PDK committees may not be expert in the field of health care and they are of diverse educational background.

Community based knowledge transfer and exchange (KTE) can be helpful to support the PDK committees. It is the process of putting knowledge into action especially by researchers or experts of any field (Wilson et al., 2010). KTE ensures the fostering of a culture that act based on research evidence, producing research evidence that is relevant to the target audience, and a continuous effort to not only link research evidence to action but to also evaluate the evidence with action (Lavis et al., 2006). This means that any research effort should be made beneficial to the community in which the data is gathered from. Furthermore, the interaction between the evidence and action will be evaluated to ensure that a better understanding of how theories are translated to practice. Experts from health care services that have the skills and knowledge based on evidence based practices can share their knowledge with the PDK committees who are mostly have secondary school education (Umar et al., 2015).

The knowledge transferred from experts to the PDK committees is suggested to positively affect work performance, job satisfaction, and self-efficacy (Umar et al., 2015). Numerous studies in the past have found a positive association between knowledge and selfefficacy (Boswell, 2013; Cordova et al., 2014; McCleary-Jones, 2011; Umar et al., 2015). Selfefficacy is a "person's judgments of their capabilities to organize and execute courses of action required to attain designated types of performance" (Bandura, 1986, p. 391). This means that individuals with high self-efficacy tend to have strong beliefs about their capabilities to execute and complete the tasks or responsibilities given to them. When applied to the PDK committees, the increase of self-efficacy would mean that they belief they are more capable to support and rehabilitate people with disability.

Self-efficacy is also associated with emotional reactions and vulnerability to stress. People with low self-efficacy tend to have higher risk of psychological distress (Aloe, Amo \& Shanahan, 2014; Bandura, 1997; Caprara et al., 2006; Van Dijik, 2009; Pedrazza et al., 2013; Shoji et al., 2015; Zajacova, Lynch, \& Espenshade, 2005). They do not believe that they have the capability to perform the tasks and responsibilities given to them which then makes them 
feel anxious, fear, and apprehension (Pedrazza et al., 2013). This applies to the PDK committees in which they may experience high psychological distress if they believe that they do not have the capability to perform their task in supporting and providing rehabilitation to the disabled people within their community. Therefore, this study aims to determine the relationship between knowledge and self-efficacy among PDK committees specifically in Pulau Pinang in addition to evaluating the relationship between self-efficacy and their psychological distress.

\section{Methods}

Participants

A cross-sectional design was implemented in the present study such that the data was gathered at a specific point of time on 22 February 2020. The data was gathered from participants of a workshop which consists of PDK committees from Pulau Pinang. The questionnaire was distributed to 36 of the PDK committees but only 32 completed the questionnaire which shows a response rate of 84.21 per cent. This is due to some of the participants leaving the workshop early before returning the questionnaire. The participants' age ranges from 22 to 55 years old and most of the participants were female (84.4\%). The highest education level of the participants was Bachelor's Degree but a huge percentage of the participants only have Sijil Pelajaran Malaysa (SPM) (53.1\%). Every participant has no physical disability that may make it difficult for them to complete the questionnaire. A brief summary of the participants' sociodemographic distribution can be seen in Table 1.

\section{Measures}

The knowledge of the participants were measured based on the information presented throughout the workshop specifically with regards to caring for children with disability. A total of 12 statements were produced based on the content of the workshop in which the participants have to response "True" of "False" for each statement. A score of one is given to the correct response while zero to the incorrect response. The total score reflects the knowledge of the participants at the end of the workshop.

An adapted Self-Efficacy Scale for Social Workers (SESSW) developed by Pedrazza and colleagues (2013) was used to measure the perceived self-efficacy of PDK committess. The scale consists of 9 items with the likert scale response of 1 to 5 with 1 representing strongly disagree while 5 representing strongly disagree. High score suggests high perceived selfefficacy while low score suggests low perceived self-efficacy. The total score from all the items measures overall perceived self-efficacy while scores from item 1, 2, and 3 measures the domain of emotion regulation; item 4,5 , and 6 measures the procedural self-efficacy domain; and item 7, 8, and 9 measures support request domain. The cronbach alpha of the current measure is .701 which is within the acceptable range.

Psychological distress was measured using the Depression, Anxiety and Stress Scale 21 (DASS-21) which was translated and validated by Ramli and colleagues (2011). The scale consists of 21 items with a likert-like response format in which the participants have to select between the range of 0 to 3 with 0 being "Never" and 3 representing "Almost Always". DASS21 can be scored based on three domains which are the depression domain, the anxiety domain, or the stress domain. Furthermore, the total score can also be used as a measure of general distress of negative affect based on Clark and Watson tripartite conceptual model 
(Clark \& Watson, 1991). In this study, the overall score will measure distress in the form of psychological distress with high score representing high psychological distress. The cronbach alpha of the scale for the current study is within the acceptable range $(\alpha=.94)$.

\section{Procedures}

All the participants were invited to a workshop organized by Faculty of Civil Engineering in collaboration with Faculty of Health Sciences, Universiti Teknologi MARA (UiTM). It was an eight hours workshop for two days with various topics presented by certified occupational therapists. The participants were brief of the questionnaire at the beginning of the workshop. The questionnaires were only distributed on the second day before the practical session in which the content of the informed consent were read out to them. They were given one hour to complete the questionnaires at their own pace in which the researchers were present to answer any inquiries. The questionnaires were then collected at the end of the workshop after the closing ceremony.

\section{Data Analysis}

Statistical Package for Social Sciences (SPSS) version 22 was used throughout the analysis process. The data was cleaned by removing outliers before descriptive statistics were calculated. Non-parametric correlation analysis was used specifically the Kendall's Tau to determine correlation coefficient due to the small sample size (Field, 2009). All variables of interest were analyzed including sociodemographic information with the significance set at $p$ $<.05$.

\section{Results}

1. Descriptive information

The mean age of the participants is 33.67 ( $S D=10.14)$ with most being female $(n=27,84 \%)$ while only five of the participants are male (15.6\%). In terms of race, all of the participants are Malay (100\%) which also reflects their religion as Islam ( $n=32,100 \%)$. A huge percentage of the participants' highest education level is SPM $(n=17,53.1 \%)$ while two with Ujian Penilaian Sekolah Rendah (UPSR) (6.3\%), six with Sijil Tinggi Persekolahan Malaysia (STPM) (18.8\%), six with diploma (18.8\%), and one with Bachelor's Degree (3.1\%). A total of 14 participants household income is within RM1000 and below (43.8\%), 13 within RM1001RM3000 (40.6\%), three within RM3001-RM4000 (9.4\%), and two with household income within RM4001-RM6000 (6.2\%). A summary of the descriptive information can be found in Table 1. 
Table 1: Participants' Sociodemographic Information

\begin{tabular}{|c|c|c|}
\hline \multirow[t]{2}{*}{ Sociodemographic } & \multicolumn{2}{|l|}{ Total } \\
\hline & $\mathrm{n}$ & $\%$ \\
\hline \multicolumn{3}{|l|}{ Gender } \\
\hline Male & 5 & 15.6 \\
\hline Female & 27 & 84.4 \\
\hline \multicolumn{3}{|l|}{ Race } \\
\hline Malay & 32 & 100 \\
\hline Chinese & 0 & 0 \\
\hline Indian & 0 & 0 \\
\hline Others & 0 & 0 \\
\hline \multicolumn{3}{|l|}{ Religion } \\
\hline Islam & 32 & 32 \\
\hline Buddhism & 0 & 0 \\
\hline Hinduism & 0 & 0 \\
\hline Christian & 0 & 0 \\
\hline Others & 0 & 0 \\
\hline \multicolumn{3}{|l|}{ Level of Education } \\
\hline UPSR & 2 & 6.3 \\
\hline PMR & 0 & 0 \\
\hline SPM & 17 & 53.1 \\
\hline SPTM & 6 & 18.8 \\
\hline Diploma & 6 & 18.8 \\
\hline Bachelor's Degree & 1 & 3.1 \\
\hline Master's Degree & 0 & 0 \\
\hline $\mathrm{PhD}$ & 0 & 0 \\
\hline \multicolumn{3}{|l|}{ Household Income } \\
\hline RM1000 and below & 14 & 43.8 \\
\hline RM1001 - RM3000 & 13 & 40.6 \\
\hline RM3001 - RM4000 & 3 & 9.4 \\
\hline RM4001 - RM6000 & 2 & 6.2 \\
\hline RM6001 and above & 0 & 0 \\
\hline
\end{tabular}

The mean score of knowledge gain throughout the workshop is 10.72 (SD=.68) which shows that most of the participants were able to retain the information provided. The self-efficacy of the participants are within the moderate range (mean=20.03, SD=3.41) while the mean for their psychological distress is 14.09 (SD=9.54) which shows a low level of psychological distress. A summary can be seen at Table 2 . 
Table 2 Descriptive Statistics of Knowledge, Perceived Self-efficacy, and Psychological Distress

\begin{tabular}{|c|c|c|c|c|c|c|}
\hline \multirow[t]{2}{*}{ Variables } & \multirow[t]{2}{*}{$\mathrm{N}$} & \multirow[t]{2}{*}{ Mean } & \multirow[t]{2}{*}{ SD } & \multicolumn{2}{|l|}{ Range } & \multirow[t]{2}{*}{$\begin{array}{l}\text { Total } \\
\text { Possible } \\
\text { Score }\end{array}$} \\
\hline & & & & Min & Max & \\
\hline 1. Knowledge & 32 & 10.72 & .68 & 10.00 & 12.00 & 12 \\
\hline 2. Perceived Self-efficacy & 32 & 20.03 & 3.41 & 13.00 & 27.00 & 45 \\
\hline 3. Emotional regulation & 32 & 4.59 & 1.16 & 2.00 & 7.00 & 15 \\
\hline 4. Procedural self-efficacy & 32 & 6.62 & 1.52 & 4.00 & 9.00 & 15 \\
\hline 5. Support request & 32 & 6.81 & 1.40 & 4.00 & 9.00 & 15 \\
\hline 6. Psychological distress & 32 & 14.09 & 9.54 & .00 & 34.00 & 63 \\
\hline
\end{tabular}

Kendall's Tau correlation was used to determine association between the variables of interest in which a significant positive relationship was found between knowledge and self-efficacy $(r=.308, p<.05)$ and specifically procedural self-efficacy $(r=.468, p<.01)$. Furthermore, a significant relationship was also found between support request efficacy and stress ( $r=308$, $\mathrm{p}<.05)$. Table 3 summarizes the Kendall's Tau correlation coefficient for each variables of interest.

Table 3: Kendall's Tau Correlation Coefficient between Knowledge, Self-Efficacy, and Psychological Distress

\begin{tabular}{|c|c|c|c|c|c|c|}
\hline Variables & Mean (SD) & 1 & 2 & 3 & 4 & 5 \\
\hline 1. Knowledge & $\begin{array}{l}10.72 \\
(.68)\end{array}$ & & & & & \\
\hline $\begin{array}{l}\text { 2. Perceived Self- } \\
\text { efficacy }\end{array}$ & $\begin{array}{l}20.03 \\
(3.41)\end{array}$ & $.308 *$ & & & & \\
\hline $\begin{array}{l}3 . \quad \text { Emotional } \\
\text { regulation }\end{array}$ & $\begin{array}{l}4.59 \\
(1.16)\end{array}$ & .113 & $.315^{*}$ & & & \\
\hline $\begin{array}{l}\text { 4. Procedural self- } \\
\text { efficacy }\end{array}$ & $\begin{array}{l}6.62 \\
(1.52)\end{array}$ & $.468 *$ & $.515 * * *$ & .269 & & \\
\hline 5. Support request & $\begin{array}{l}6.81 \\
(1.40)\end{array}$ & -.058 & $.482 * *$ & .236 & $.362 *$ & \\
\hline $\begin{array}{l}\text { 6. Psychological } \\
\text { distress }\end{array}$ & $\begin{array}{l}14.09 \\
(9.54)\end{array}$ & -.029 & .096 & .329 & .012 & $.302 *$ \\
\hline
\end{tabular}

${ }^{*} \mathrm{p}<.05 ;{ }^{* *} \mathrm{p}<.01 ; * * * \mathrm{p}<.001$

\section{Discussion}

The aim of the study was to determine the relationship between knowledge, self-efficacy and psychological distress among PDK committees in Pulau Pinang. The PDK committees attended a workshop with occupational therapist as their speakers providing theoretical and practical knowledge. Towards the end, they were able to withhold the information provided to them which is reflected by how most of them answered the questions correctly. The increase in knowledge is then positively associated to their self-efficacy. This is consistent with numerous past studies (Boswell, 2013; Cordova et al., 2014; McCleary-Jones, 2011; Umar et al., 2015) such that when individuals knowledge increases, their beliefs about their capabilities to complete the tasks and responsibilities given to them also increases. The finding suggests that increasing the knowledge of PDK committees will benefit them in terms of making them 
believe in their capabilities to contribute to the communities regardless of their educational background. Furthermore, the increase in knowledge was also found to significantly increase the PDK committees judgment of their ability to follow procedures. This is especially important when dealing with children with disabilities since there are many standard operating procedures that they have to follow to avoid liability.

Knowledge was not found to be significantly associated with psychological distress which is not consistent with previous findings (Alavi et al., 2016; Shadi et al., 2017). It is suggested by findings from Shadi and colleagues (2017) that an increase in knowledge would mean that individuals would also be able to manage their stress better. However, the knowledge assessed in this study specifically measures knowledge obtained from the workshop. This suggests that the increase of knowledge with regard to managing children with disability does not decrease nor increase their psychological distress.

Self-efficacy was found to be significantly associated to psychological distress. Specifically, an increase in self-efficacy in terms of support request was found to increase the experience of distress among PDK committees. The finding is inconsistent with previous studies that found a significant negative relationship between self-efficacy and psychological distress (Aloe et al., 2014; Bandura, 1997; Caprara et al., 2006; Van Dijik, 2009; Pedrazza et al., 2013; Shoji et al., 2015; Zajacova et al., 2005). Aloe and colleagues (2014) did a research on teachers to determine how the self-efficacy predicts their risk of burnout which is a form of physical and emotional distress. They found that the increase in the beliefs about teachers' capability to manage their classroom ensures that they do not feel emotionally exhausted when completing their responsibilities as teachers. A meta-analysis by Shoji and colleagues (2015) also found a similar interaction between self-efficacy and burnout. Based on their findings, the self-efficacy of health care workers is associated with their risk of burnout such that health care workers who beliefs they do not have the capability to provide optimum health care services tend to feel that they have to work harder consequently increase their emotional exhaustion. However, the current study found that PDK committees who have high beliefs about their capabilities to seek support in completing their task tend to feel psychologically distress.

The discrepancies could be due to the differences of perception towards support seeking behaviour among the PDK committees. It is possible as findings from a study by Podolski and Nigg (2001) found that parents who seek social support were also found to be significantly distress. One explanation is support required by the parents can be too demanding for individuals who are providing the support which lead them to isolate the parents. Furthermore, it can be challenging for the parents to face those who continuously provide support when the problem is not resolved. Therefore, it is possible that even when the PDK committees' believe that they are capable to seek help from their colleagues to complete their task; they feel that it can be too demanding for their colleagues and creates a negative impression. This can be true especially due to the challenging work with disabled people in which every PDK committees tend to be highly occupied.

\section{Limitation and Recommendation}

Due to the nature of the research in which it is a preliminary study, a bigger sample size and a robust statistical analysis can be done to determine the correlation and the variance 
between each predictor. Moreover, mediation analysis can be conducted with a bigger sample size. Additionally, the method of action research can also be applied in which data is collected before and after the workshop to identify the effectiveness of KTE.

\section{Conclusion}

Knowledge obtained from workshop by experts in the field can be very helpful for PDK committees or any organization that provide services to the community regardless of their educational level. The increase of knowledge can significantly increase their beliefs about their capabilities to complete their tasks. Additionally, it is important to also find proper strategies to ensure that the well-being of the PDK committees or individuals who work with community is safeguarded. These people are working very hard to not only rehabilitate the disabled in order for them to act as part of the community but also support and motivate disabled people and their family members, raise awareness of the community of the existence of disabled people who need support, and hopefully forming a caring society

\section{Acknowledgment}

The study was made possible with the support of faculty members from Faculty of Civil Engineering and Faculty of Health Sciences with approval from UiTM Pulau Pinang branch to organize the workshop. Additionally, the researchers also appreciate the support from DSW and PDK centers in Pulau Pinang for attending the workshop and participate in the research.

\section{Corresponding Author}

Qarem Mohamed Mustafa

Faculty of Health Sciences, UiTM Cawangan Pulau Pinang, Malaysia

Faculty of Health Sciences, UiTM Cawangan Pulau Pinang Kampus Bertam, 13200, Kepala Batas, Penang, Malaysia

Email: qaremuitm@gmail.com

\section{References}

Kuna, K. (1998). Community-based rehabilitation in South East Asia: Case studies from Indonesia and Malaysia. [Unpublished master's thesis]. School of Development Studies of the University of East Anglia.

Pelan strategik Jabatan Kebajikan Masyarakat 2016-2020. (2017). Jabatan Kebajikan Masyarakat: Malaysia.

Wilson, M. G., Lavis, J. N., Travers, R., \& Rourke, S. B. (2010). Community-based knowledge transfer and exchange: Helping community-based organizations link research to action. Implementation Science, 5(1). https://doi.org/10.1186/1748-5908-5-33

Lavis, J. N., Lomas, J., Hamid, M., \& Sewankambo, N. K. (2006). Assessing country-level efforts to link research to action. Bulletin of the World Health Organization, 84, 620-628.

Umar, S., Rahman, A. A., Daud, A., ... Van Rostenberghe, H. (2015). Effects of education modules on the job dissatisfaction of teachers in community-based rehabilitation centres in Kelantan, Malaysia. Educaion in Medicine Journal, 7(2), 1-8.

Boswell, S. S. (2013). Undergraduates' perceived knowledge, self-efficacy, and interest in social science research. The Journal of Effective Teaching, 13(2), 48-57. Retrieved from http://www.uncw.edu/jet/articles/vol13_2/boswell.pdf

Cordova, J. R., Sinatra, G. M., Jones, S. H., Taasoobshirazi, G., \& Lombardi, D. (2014). Confidence in prior knowledge, self-efficacy, interest and prior knowledge: Influences 
on conceptual change. Contemporary Educational Psychology, 39(2), 164-174. https://doi.org/10.1016/j.cedpsych.2014.03.006

McCleary-Jones, V. (2011). Health literacy and its association with diabetes knowledge, selfefficacy and disease self-management among African Americans with diabetes mellitus. The ABNF Journal : Official Journal of the Association of Black Nursing Faculty in Higher Education, Inc, 22(2), 25-32.

Bandura, A. (1986). Social Foundations of Thought and Action: A Social Cognitive Theory. Englewood Cliffs: Prentice-Hall.

Aloe, A. M., Amo, L. C., \& Shanahan, M. E. (2014). Classroom Management Self-Efficacy and Burnout: A Multivariate Meta-analysis. Educational Psychology Review, 26(1), 101-126. https://doi.org/10.1007/s10648-013-9244-0

Bandura, A. (1997). Self-Efficacy: The Exercise of Control. New York: Freeman.

Caprara, G. V., Steca, P., Gerbino, M., Paciello, M., \& Vecchio, G. M. (2006). "Looking for adolescents' well-being: Self-efficacy beliefs as determinants of positive thinking and happiness." Epidemiologia e Psichiatria Sociale, 15, 30-43.

Van Dijk, M. (2009). Employee self-efficacy and job stress during organizational change: the mediating effect of risk perception. Utrecht: University of Twente.

Pedrazza, M., Trifiletti, E., Berlanda, S., \& Bernardo, G. A. (2013). Self-efficacy in social work: Development and initial validation of the self-efficacy scale for social workers. Social Sciences, 2(3), 191-207. https://doi.org/10.3390/socsci2030191

Shoji, K., Cieslak, R., Smoktunowicz, E., Rogala, A., Benight, C. C., \& Luszczynska, A. (2016). Associations between job burnout and self-efficacy: A meta-analysis. Anxiety, Stress and Coping, 29(4), 367-386. https://doi.org/10.1080/10615806.2015.1058369

Zajacova, A., Lynch, S. M., \& Espenshade, T. J. (2005). Self-efficacy, stress, and academic success in college. Research in Higher Education, 46(6), 677-706. https://doi.org/10.1007/s11162-004-4139-z

Musa, R., Ramli, R., Abdullah, K., \& Sarkarsi, R. (2011). Concurrent validity of the depression and anxiety components in the Bahasa Malaysia version of the Depression Anxiety and Stress Scale (DASS). ASEAN Journal of Psychiatry, 12(1).

Clark, L. A., \& Watson, D. (1991). Tripartite model of anxiety and depression psychometric evidence. Journal of Abnormal Psychology, 100(3), 316-336.

Field, A. (2009). Discovering statistics using SPSS (3rd Edition). London: Sage Publications.

Alavi, S. S., Dabbagh, T. S., Abbasi, M., \& Mehrdad, R. (2016). Radiation protection knowledge, attitude and practice (RP-KAP) as predictors of job stress among radiationworkers in Tehran Province, Iran. Iranian Red Crescent Medical Journal, 18(10). https://doi.org/10.5812/ircmj.29394

Shadi, M., Peyman, N., Taghipour, A., \& Tehrani, H. (2017). Predictors of the academic stress and its determinants among students based on the theory of planned behavior. Journal of Fundamentals of Mental Health, 20(1), 87-98.

Podolski, C. L., \& Nigg, J. T. (2001). Parent stress and coping in relation to child ADHD severity and associated child disruptive behavior problems. Journal of Clinical Child Psychology, 30(4), 503-513. 